5 Avery, Fletcher, Williams. The lung and its disorders in the newbom infant. 4th Edition, 1981, W.B. Saunders Co. p

\section{The anaesthetic monitors}

\section{Why monitor?}

Everything done in anaesthesia carries some risk for the patient. A reduction in risk relates directly to greater safety in the operating room and forms the rational basis for anaesthesia monitors.

Recent reviews on deaths related to anaesthesia ${ }^{1-3}$ indicate some relevant facts (Table I). In these studies it was demonstrated that 2,000 to 4,000 deaths related to anaesthesia occur per year in the reporting countries. Fifty to ninety per cent of these deaths were due to human error and in most instances were judged to have been preventable. One study ${ }^{2}$ indicated that one such death per anaesthetists' lifetime could be expected and that, on average, 4.3 human error near-incidents for every one of these deaths were likely. All three studies ${ }^{1-3}$ suggested that human error was often related to the level of vigilance and vigilance can be enhanced by monitors. ${ }^{1}$ Automated apparatus, properly programmed with alarm limits can more reliably carry out repetitive tasks than humans can.'

Patients are now presenting at high risk levels and as the risk level increases, so does mortality in the postoperative period according to recent studies. ${ }^{4,5}$

When the most common errors of management and preventable incidents during anaesthesia man-

\section{TABLE I Why monitor?}

Deaths related to anaesthesia - 2000-4000 per annum ${ }^{1-3}$ 50-90\% of deaths - human error

Deaths preventable ${ }^{1-3}$

One such death/anaesthetist ${ }^{2}$

4.3 (av) Human errors neas incidents/one death ${ }^{2}$

Human error related to level of vigilance'

Vigilance enhanced by monitors'

Higher risk patient trend ${ }^{4}$

Higher ASA risk = increased mortality ${ }^{3}$
TABLE II Common preventable incidents during anaesthesia management*

Breathing system disconnection

Breathing system leak

Breathing system misconnection

Lass of $\mathrm{O}_{2}$ or $\mathrm{N}_{2} \mathrm{O}$ supply

Inadvertent change in gas flow

Oesophageal or endobronchial intubation

Hypoventilation (operator error)

Ventilator malfunction

*Modified from Cooper'

agement (Table II) are listed, it is striking when one realizes how many of these clinical situations could have been monitored in routine fashion and how the outcome might thus have been changed. Lunn and Mushin $^{3}$ produce surprising evidence that the provision of essential monitoring instruments is inadequate and, even more significant, where they are available they are not always used, despite the fact that 72 per cent of patients were regarded preoperatively by anaesthetists as "poor" or "moribund."

There is a consensus from three reviews of deaths related to anaesthesia, ${ }^{1-3}$ that the use of monitors can aid in avoiding preventable deaths.

II What and how should I monitor?

Monitoring may be classified as minimum, which is usually non-invasive and special which can be invasive. "Invasive" usually implies entry through mucous membrane or skin.

\section{A Minimum (non-invasive) manitoring}

Table III lists minimum standards in monitoring in routine clinical care, which are non-invasive.

There is a distinct trend to the use of non-invasive (or relatively non-invasive) monitoring techniques, because of improvements in reliability, accuracy and automation. The ease of application and reduced chance of complications offer great appeal.

\section{B Special monitoring (often invasive)}

Invasive monitoring does not guarantee accuracy and reliability. Complications with invasive monitoring are well documented. ${ }^{6}$ Special monitoring techniques are listed in Table IV. Modifications of basic equipment are occurring constantly with technological advances. For instance, the recent introduction of disposable pressure transducers provides prepackaged compact, sterile, pre-assembled, pre- 
TABLE III Minimum standards in monitoring in routine clinical care

\begin{tabular}{l}
\hline Arterial blood pressure \\
1. Cuff-auscultation \\
2. Oscillotometer* \\
(a) Automated \\
(b) Aneroid sphygmomanometer \\
Doppler $\dagger$ \\
3. Ultrasound \\
ECG \\
Ventilator alarms \\
1. Disconnect \\
2. Volume \\
3. Pressure \\
4. Flow rate \\
5. Oxygen ratio \\
Spirometer \\
1. Tidal volume \\
2. Minute volume \\
Oxygen analyzer \\
Temperature (skin, rectal, oesophageal, oropharyngeal) \\
Neuromuscular junction function \\
Urine \\
Precordial oesophageal stethoscope
\end{tabular}

*Ear oximetry, End-tidal $\mathrm{CO}_{2}, \mathrm{Pte} \mathrm{CO}_{2}$ and $\mathrm{PtcO}_{2}, \mathrm{EEG}$ †Might not be available for routine care.

calibrated units. This kind of advance reduces problems and complications with apparatus and ensures greater degree of accuracy and reliability of results, to say nothing of reducing the stress of the anaesthetist involved in the setting-up such instrumentation.

\section{Iv New ideas (new technology)}

Table $V$ lists some new ideas that have been developed in the field of anaesthetic monitors.

\section{TABLE IV Special monitoring}

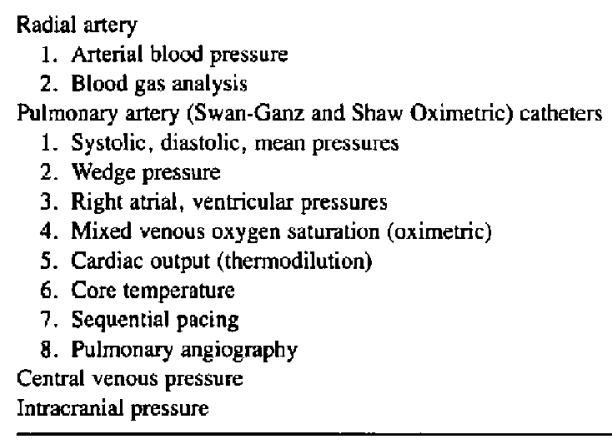

\section{Intraoesophageal multiparameter monitor}

The relatively non-invasive route of being able to monitor multiple vital functions by one single technique from one site has strong appeal and many advantages over other forms of monitoring during anaesthesia. $^{7}$

The oesophageal stethoscope has been available for considerable time. Only recently has temperature monitoring, incorporated into the stethoscope, been commercially available. Even more recently, Kaplan's group ${ }^{8}$ have reported on their experience with an oesophageal lead for intraoperative electrocardiographic monitoring. At the time of writing there is no commercially available multiparameter oesophageal monitor. Our prototype monitor, currently undergoing clinical evaluation during anaesthesia, is capable of monitoring, recording and displaying visually and audibly, heart sounds, breath sounds, EOG and body temperature. ${ }^{7}$ Ideally, the capability of also monitoring cardiac function (cardiac output) by means of transoesophageal two-dimensional (2-D) echocardiography ${ }^{9}$ would be desirable. The feasibility of incorporating this module into our prototype is now under study.

\section{2 "Smart" disconnect ventilator monitor 10,11}

Despite significant improvements in the safety of anaesthetic equipment in recent years, disconnection in the patient breathing system remains one of the most common types of preventable anaesthetic mishaps. Many currently available breathing system monitors cannot reliably detect several hazardous conditions.

An improved breathing system monitor has been developed ${ }^{10,11}$ that reliably detects many hazardous conditions under realistic conditions of simulation. The software algorithm in this monitor stores the normal pressure waveform in the patient circuit, evaluates the ongoing waveform in the patient circuit in terms of a set of absolute and relative criteria, and warns the operator when such criteria are not satisfied.

Also, alams for absolute criteria exist which include "Dead Battery," "Malfunction," "High/ Low Pressure," "Negative Pressure," "I/E Ratio."

3 Computerized EEG: Compressed spectral array and dot density image (power spectral analysis) The development of power spectral analysis of the EEG using digital computer techniques has led to 
TABLE V New ideas (and technology) in monitors

I. Intraoesophageal multiparameter monitor

(a) Heart sounds

(b) Breath sounds

(c) ECG

(d) Temperature

(e) Cardiac function (2-D-echocardiography)

2. "Smart" disconnect ventilator monitor

3. Computerized EEG! compressed spectral array and dot

4. Sensory-eyoked potentials density image

(a) Somatosensory

(b) Brainstem auditury

(c) Visual

5. Mixed venous oxygen saturation (Oximetric)

6. Mass spectrometry: inspired/expired gas analysis $\mathrm{CO}_{2}, \mathrm{CO}_{2}$ $\mathrm{N}_{2} \mathrm{O}, \mathrm{N}_{2}$, halothane, ethrane, isoflurane)

7. Computer-based paticnı monitoring

8. Monitoring the operating room environment:

(a) Anaesthetic pollution

(b) Bacterial, viral contamination

(c) Electrical hazards

renewed interest in the EEG as an aid in the monitoring of anaesthetic depth, the state of cerebral cortical function under cardiopulmonary bypass, and during carotid endarterectomy. ${ }^{12,13}$

Compressed EEG data facilitate recognition of trends of change by the untrained clinician and permit closer integration of EEG activity with the clinical situation. Despite consolidation and mobility of equipment, continued technical, personnel availability, interpretation aspects and cost factors are considerations that have not yet made this monitoring module universally acceptable and applicable.

\section{Sertsory-evoked potentials (SEP)}

The current state of the art in intrdoperative monitoring of sensory-evoked potentials has been reviewed recently by Grundy. ${ }^{14}$ Basically, SEP are the electrophysiologic responses of the nervous system to sensory stimulation. The three clinically applicable stimulated responses are somatosensory, brain stem auditory, and visual-evoked potentials. They reflect the functional integrity of these specific sensory pathways and serve to some extent as general indicators of function in adjacent structures. Deteriorating neurologic function can be detected early, so that the surgeon and/or anaesthetist can intervene to improve function and minimize the possibility of permanent damage to the nervous system. Significant advances have been made in equipment, enabling standardized formats of stimulation and recording in a more simplified manner, but it still remains somewhat bulky, not always easily portable, requiring additional electrical isolation and is expensive. ${ }^{14}$ Technical problems can cloud the observations and might be the source of difficulties in interpretation. There will, however, be increasing acceptability for this form of monitoring for selected neurosurgical, orthopaedic and vascular procedures.

5 Continuous mixed venous oxygen saturation $\left(S V_{O_{2}}\right.$ ) monitoring (Shaw/Oximetric catheter)

The development of a new fiberoptic catheter (Oximetric Shaw ${ }^{\mathrm{T}+1}$ Catheter Oximeter System, Oximetric Inc., Mountain View, Calif.) has made it possible to carry out continuous measurements of mixed venous oxygen saturation $\left(\mathrm{SV}_{\mathrm{O}_{2}}\right)$. It is useful in the monitoring and care of critically ill patients during and after operation. ${ }^{\text {Is }}$ It indicates the nonspecific haemodynamic status of the patient, and each haemodynamic variable must be assessed if there are changes of more than ten per cent in the $\mathrm{SV}_{\mathrm{O}_{2}}$ value. ${ }^{15}$

The Shaw Oximetric catheter is a balloon-tipped, flow-directed, thermodilution pulmonary artery fiberoptic catheter. Catheter ports allow simul taneous blood sampling, arterial blood and central venous pressure, temperature and cardiac output monitoring. Similar complications are inherent in this catheter as can occur with the Swan-Ganz pulmonary artery catheter.

\section{Medical mass spectrometer}

The ability to monitor inspired and expired gases on a continuous basis during anaesthesia has obvious merit in enhancing safety in the operating room. Advances in mass spectrometry technology have now made it possible to analyze sequentially up to 16 operating rooms for eight different gases, usually oxygen, carbon dioxide, nitrous oxide, nitrogen, enflurane, isoflurane, halothanc. Two systems are currently available: that for anacsthetic and respiratory analysis (SARA) (Chemetron) ${ }^{16}$ and the respiratory monitoring system (RMSIII) of the Perkin-Elmer Corporation. ${ }^{17}$

In centres where these systems are operative, experience is generally favourable. ${ }^{18-20}$ They cannot be relied upon as apnoeic or disconnect alarms 
since time between successive sampling of each room is not less than one minute and could be up to two to three minutes. Increased safety of general anaesthesia is provided by continuous information on anaesthetic gas composition. Sudden decrease in $\mathrm{PaCO}_{2}$ or sudden appearance and increase of nitrogen has provided early indication of air embolization. ${ }^{20}$ Increases of $\mathrm{PaCO}_{2}$ have identified early problems with breathing circuit (expiratory valves) malfunction. Unexpected vapour concentrations different from those believed to being delivered, have been frequently discovered. There can be greater confidence in using low-flow anaesthetic techniques and the system may be applied to monitoring operating room pollution and assessing the efficacy of scavenging systems in the operating room.

When considering what costs would be involved to provide separate analyzing units for each gas for every operating room in a surgical suite, the costs of installation and maintenance of the mass spectrometer are favourable.

7 Computer-based patient monitoring is already an integral part of sophisticated anaesthetic monitoring. Computer programming will expand in the future and find widespread applications and acceptance by anaesthetists as an aid to increasing safety in the operating rooms.

\section{Monitoring the operating room equipment}

The anaesthetic monitors should also deal with safety in the operating room as it pertains to the environment in which operating room personnel work.

The Foxboro/Wilks Miran Portable, Rapid Infrared analyzer (MIRAN-101, 103 and 201) is capable of detecting trace concentrations of, for example nitrous oxide (down to $0.14 \mathrm{ppm}$ ) and halothane (down to $0.16 \mathrm{ppm}$ ). The 1977 proposed standards of permissible levels (National Institute for Occupational Safety and Health - NIOSH) for nitrous oxide are $25 \mathrm{ppm}$ and $2 \mathrm{ppm}$ halothane. ${ }^{21}$

Monitoring the operating room environment for bacterial and viral (especially infectious hepatitis and auto immune deficiency syndrome (AIDS)), contamination and for electrical hazards to personnel of the monitoring equipment itself also merit consideration.

\section{Iv Concluding comment}

Of the various monitoring modalities, the anaes- therists' senses of sight, hearing and touch are still the most important. Monitoring devices are basically extensions of these senses and should be applied where appropriate and applicable for their enhancement and as means of communicating with the anaesthetized patient.

The anaesthetist must correctly interpret the information presented by monitors in order to react with the appropriate comective intervention ${ }^{22}$ and thereby improve safety in the operating room.

\section{References}

1 Cooper JB, Newbower RS, Long CD. Preventable anesthesia mishaps - a study of human factors. Anesthesiology 1978; 49: 399-406.

2 Special Committee Investigating Deaths under Anaesthesia: Report of 745 ciassified cases, 19601968. Med J Australia 1970; 573-94.

3 Lunn JN, Mushin WW. Mortality associated with anesthesia. Assoc of Anaesth of Great Britain \& Ireland, Nuffield Provincial Hospital Trust, London, 1982; p. 66.

4 Jenkins LC. (Statistical Data - V.G.H. 1983) Unpublished.

5 Turnbull KW, Fancourt-Smith PF, Banting GC. Deaths within 48 hours of anesthesia at the V.G.H Can Anaesth Soc J 1980; 27: 159-63.

6 Baigrie RS, Morgan CD. Hemodynamic monitoring: Catheter insertion techniques, complications and trouble-shooting. Can Med Assoc J 1979; 12I: 885-92.

7 Jenkins LC, Samer K, McEwen J. Intraesophageal multiparameter monitor for anesthesia. Submitted for publication.

8 Kares RA, Zaidan JR, Kaplan JA. Esophageal lead for intraoperative electrocardiographic monitoring. Anesth Analg 1982; 61: 781-5.

9 Cahalan $M K$, Kremer $P$, Schiller $N B$, et al. Intraoperative monitoring with two-dimensional transesophageal echocardiography. Anesthesiology 1982; 57: A153.

$10 M C E$ wen $J A$, Small $C F$, Jenkins LC. A smart disconnect monitor for anesthetic equipment. Dig 8th Canadian Med Biol Eng Conf 1980; 129-130. (Nat Res Council, Ottawa, Canada.)

11 McEwen $J A$, Jenkins $L C$. Complications of and improvements to breathing circuit monitors for anesthesia ventilating. Medical Instrumentation 1983; 17:70-4.

12 McEwen JA, Anderson GB, Jenkins LC, Saunders $B A_{r}$ Low $M D$. EEG spectra during impaired con- 
sciousness and anesthesia. Electroenceph Clin Neurophysiol 1973; 34: 724.

13 Berezowsinj JL, McEwen JA, Anderson GB, Jenkins $L C$. A study of anesthesia depth by review spectral analysis of the EEG. Can Anaesth Soc J 1976; 23: $1-8$.

14 Grundy $B L$. Medical intelligence: intraoperative monitoring of sensory-evoked potentials. Anesthesiology 1983; 58: 72-87.

15 Jamieson WRE, Turnbull $K W$, Laurier AJ, Dodds $W A$, Allison JC, Tyers GFO. Continuous monitoring of mixed venous oxygen saturation in cardiac surgery. Can J Surgery 1982; 25: 538-43.

16 SARA Operators Handbook, Chemetron Medical Division, Allied Health Care Products, St. Louis, Minnesota. (Form No. 40-00-1006-S 188-122-001 June 1981 and Form No. 40-00204S 168-139-001, March 1982.)

17 RMSIII Product Brochure, Perkin-Elmer Incorp., Ramona, Calif. 1983.

18 Ozanne GM, Young WG, Mazzei WJ, Severinghaus $J W$. Multipatient anesthetic mass spectrometry: Rapid analysis of data stored in long catheter. Anesthesiology 1981; 55: 62-70.

19 Boyd GG. Solarmonsen RF. Remote monitoring by mass spectrometry during anesthesia. Br J Anesth 1982; $54: 15$

20 Severinghaus $J W$. Air embolism detected by mass spectrometry. Anesthesiology News (Sept) 1982; 8: (9).

21 Foxboro Analytical Bulletin L-16A-10M-10/78, 1978.

22 Blist $C D$. Monitoring during outpatient anesthesia. International Anesthesiology Clinics 1982; 20: $17-25$

\section{Medico-legal factors in operating room safety}

\section{Introduction}

The problem of litigation in anaesthesia has increased greatly in the post-war era of practice. The simplest demonstration is provided by a projected increase in
CMPA (Canadian Medical Protective Association) fees for full-time anaesthetists to nearly $\$ 3,000.00$ per year, a 300 -fold increase in this same period. This coincides with a 70 -fold increase in bed-rates, and a much smaller rise in physicians' incomes.

The rapid rise in the requests for assistance, compared to the much slower increase in membership is shown in Figures 1 and 2.

\section{Sources}

Information for this paper is derived mainly from interviews with C.M.P.A. counsel (legal and medical), annual reports of CMPA, literature survey; and from personal participation.

\section{Components of negligence}

A charge of civil negligence might arise when three conditions are met:

(1) A duty of care is shown to exist between patient and anaesthetist;

(2) A breach of this duty of care is alleged to bave taken place;

(3) As a result of this breach, damage is al leged to have occurred. A cause-and-effect relationship between breach and damage must be demonstrated.

Criminal negligence may be charged when actions are alleged to have been taken in reckless disregard of the consequences. This charge is rare in Canada. Lack of informed consent is alleged in some cases, and might lead to a charge of battery, that is the unauthorized "laying-on" of hands.

In negligence trials, the standards of the profession as outlined by expert witnesses are not preemptive, and the court may impose obligations of practice beyond those presented. The circle of potential claimants has greatly widened by family law reform in Canada, with the entitlement of collateral relatives to seek compensation for loss of support and companionship

Historically, anaesthesia-related injuries arise from the drugs and techniques in common use during a particular era:

(1) Chloroform and diethyl ether accounted for many fatalities in the $1840-1920$ period, with litigation being rare;

(2) Nitrous oxide in the 1920-40 period, often in hypoxic mixtures.

(3) In the post-war era, spinal-cord injuries from contaminated solutions used in spinal analgesia 